\title{
Analysis of Terrain Height Effects on the Asymmetric Precipitation Patterns during the Landfall of Typhoon Meranti (2010)
}

\author{
Jinqing Liu ${ }^{1,2}$, Ziliang $\mathrm{Li}^{1}{ }^{*}$, Mengxiang $\mathrm{Xu}^{1}$ \\ ${ }^{1}$ College of Oceanic and Atmospheric Sciences, Ocean University of China, Qingdao, China \\ ${ }^{2}$ Hunan Meteorological Observatory, Changsha, China \\ Email: ^liziliang@ouc.edu.cn
}

How to cite this paper: Liu, J.Q., Li, Z.L. and Xu, M.X. (2019) Analysis of Terrain Height Effects on the Asymmetric Precipitation Patterns during the Landfall of Typhoon Meranti (2010). Atmospheric and Climate Sciences, 9, 331-345. https://doi.org/10.4236/acs.2019.93024

Received: May 25, 2019

Accepted: July 8, 2019

Published: July 11, 2019

Copyright $\odot 2019$ by author(s) and Scientific Research Publishing Inc. This work is licensed under the Creative Commons Attribution International License (CC BY 4.0).

http://creativecommons.org/licenses/by/4.0/

\section{c) (i) Open Access}

\begin{abstract}
The predictions of heavy rainfall in an accurate and timely fashion are some of the most important challenges in disastrous weather forecast when a typhoon passes over land. Numerical simulations using the advanced weather research and forecasting (WRF) model are performed to study the effect of terrain height and land surface processes on the rainfall of landfall typhoon Meranti (2010). The experimental results indicate that terrain height could enhance convection and precipitation. The heavy rainfall is concentrated on the west side of typhoon track, which is mainly associated with the distribution of deep convection. The terrain height exacerbated the asymmetric distribution of heavy rainfall. The most striking feature is that enhanced rainfall is mainly caused by secondary circulation, which is induced by terrain height and can be explained by a highly simplified theoretical model. Finally, it is worth pointing out that perturbation potential temperature or buoyancy processes forced by terrain height could be taken as an indicator for accurate prediction of heavy rainfall during the landfall of a tropical cyclone.
\end{abstract}

\section{Keywords}

Typhoon, Asymmetry, Topography, The Secondary Circulation

\section{Introduction}

Heavy rainfall within a landing typhoon will bring significant economic losses and a serious threat to lives [1] [2] [3]. A number of studies have shown that typhoon rainstorms are not only controlled by its inner core structure and inten- 
sity [4] [5], but also largely affected by its large-scale circulations and their interaction with land surface processes [6] [7]. Accurate prediction of heavy rainfall within a typhoon at landfall can help to reduce the loss of lives and property. However, there are still many uncertainties in the prediction of typhoon precipitation, which are mainly affected by complex terrain and asymmetric convection in typhoon [8].

Landing typhoon convection and rainfall asymmetry are associated with many factors, including environmental vertical wind shear, typhoon movement and land surface processes [8]. A number of studies provide some evidence of rainfall and convection asymmetry induced by vertical wind shear [9]. The vertical wind shear is considered as a key factor affecting typhoon rainfall asymmetry when a typhoon passes over land [10].

The impacts of land surface on typhoons are mainly related to surface friction and terrain dynamic effects [11]. During typhoon landfall, the elevated terrain and land surface change could affect rainfall distribution and transient structures in typhoons [12] [13]. The remarkable influence of terrain on typhoons is that the surface friction reduces the typhoon intensity when a typhoon passes over land. However, elevated terrain can enhance convection, which in turn also affects typhoon structure change and rainfall distribution [11]. As a typhoon went across land, heavy rainfall can occur over elevated terrain areas. The elevated terrain can induce ascending motions, which may lead to rainfall and structure change during the landfall of a typhoon [14]. The primary goal of this study is to investigate the predictability of typhoon heavy rainfall at landfall, and understand the role of terrain height and land surface processes in the structure and rainfall of landfall typhoon Meranti (2010). The rest of this manuscript is organized as follows. Section 2 briefly describes typhoon Meranti (2010). The design of sensitivity experiments is presented in Section 3. The results of experiments (oceanic, no-terrain and complete terrain) are shown and discussed in Section 4. The simple theoretical model is developed and the results of experiments are explained in Section 5. Main conclusions are drawn in the last section.

\section{Synoptic Situation}

Typhoon to be investigated is Meranti (2010) since it brought heavy rainfall to the southeast coastal Provinces of China. On 7 September 2010, Meranti (2010) formed as a tropical depression in the western North Pacific. By 06:00UTC, 8 September, it was upgraded into a tropical storm. The Joint Typhoon Warning Center (JTWC) reported that the tropical storm rapidly intensified into a typhoon, from 18:00UTC, 8 September to 18:00UTC, 9 September. By 19:30UTC, 9 September, typhoon Meranti (2010) weakened rapidly making landfall and brought heavy rainfall to Fujian and Zhejiang Provinces of China. However, the real-time weather forecast released by China Meteorological Observatory (CMO) and the National Centers for Environmental Prediction (NCEP) failed to capture the rainstorm case in Fujian Province of China (Figure 1). 


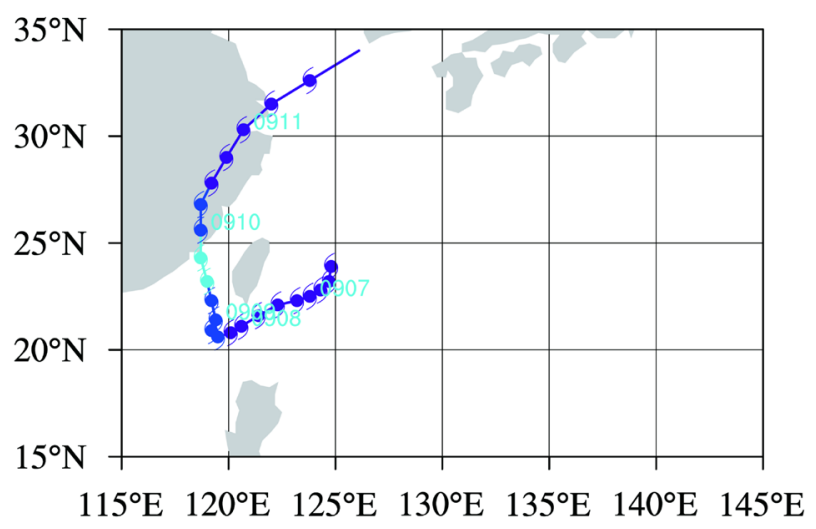

(a)

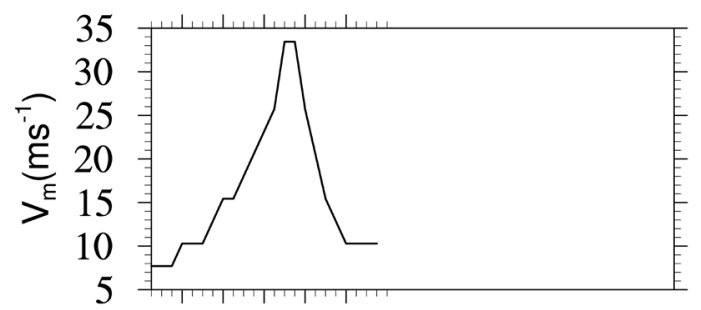

7891011

Year:2010 Month:9 Day=6-11

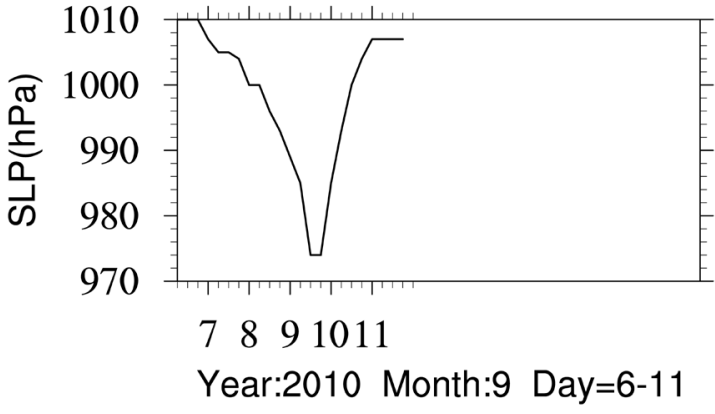

(b)

Figure 1. The track (a); and intensity (b) change of the Meranti (2010) (minimum central pressure and maximum wind speed) from the JTWC best-track data.

Satellite imagery (Figure 2(a), the MTSAT images from Kochi University) showed clearly a frontal cyclone shaped pattern at 16:00UTC on September 9, 2010. This storm began to quickly lose its frontal structure and acquire typhoon shaped pattern at 18:00UTC on September 9th. After landfall, Meranti (2010) gradually remained as a comma cloud with frontal structure at 02:00UTC on September 10, 2010. Black body temperatures (TBB) can directly reflect deep convection, which are obtained from Feng-Yun (FY) 2 series Geostationary Meteorological Satellite (Yang et al., 2016). Figure 2(b) indicates that convection asymmetry plays an important role in typhoon asymmetric rainfall. It can be seen that the strongest identified MCSs is located on the left side of typhoon Meranti (2010) moving direction. The low TBB matched well with asymmetric heavy rainfall within the core of typhoon Meranti (2010). 


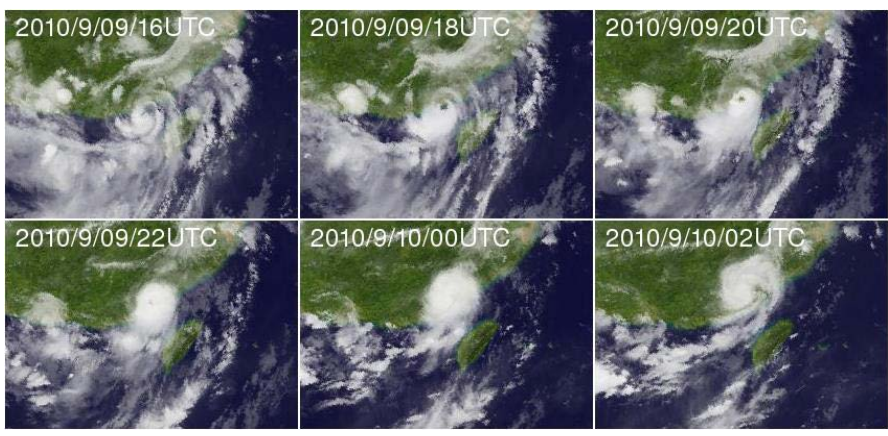

(a)
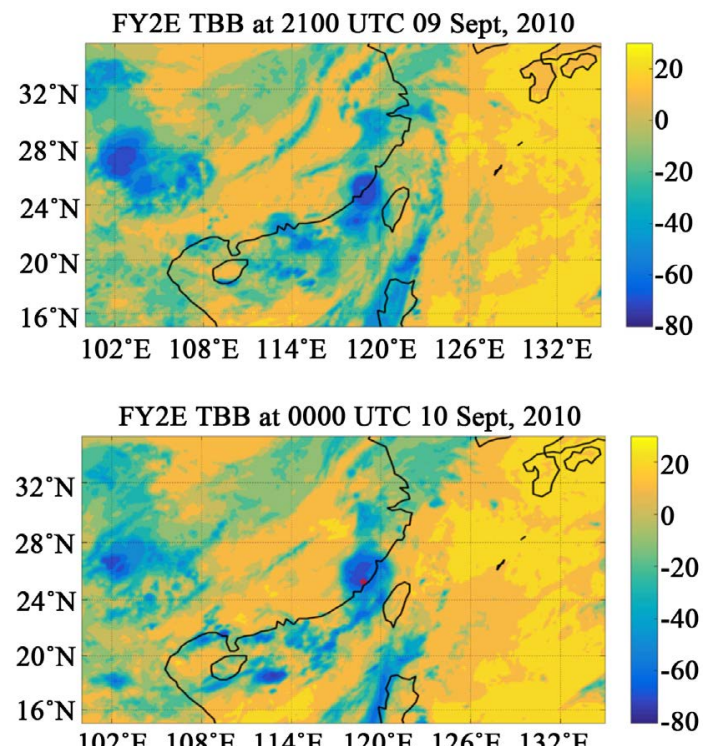

$102^{\circ} \mathrm{E} \quad 108^{\circ} \mathrm{E} \quad 114^{\circ} \mathrm{E} \quad 120^{\circ} \mathrm{E} \quad 126^{\circ} \mathrm{E} \quad 132^{\circ} \mathrm{E}$

(b)

Figure 2. (a) Satellite observation of Typhoon Meranti, from 16:00UTC 09 to 04:00UTC 10 September 2010. The MTSAT images are provided by Kochi University; (b) Identified TBB of Meranti (2010), 21:00UTC 09 (top) 00:00UTC 10 (bottom) September 2010. TBB data from FY 2 Series Geostationary Meteorological Satellites.

\section{Methodology}

The weather model employed in this case study is the Advanced Research WRF (ARW) model (version 3.3) and its vortex bogus scheme [15]. All experiments have three two-way nested domains with $49 \times 49$ (D01), $103 \times 109$ (D02) and $205 \times 244$ (D03) horizontal grid points and horizontal grid spacing of $27 \mathrm{~km}, 9$ $\mathrm{km}$ and $3 \mathrm{~km}$, respectively. All the three domains have 47 sigma $(\sigma)$ levels with model top at $48 \mathrm{hPa}$. The physics options chosen in this study include the Kain-Fritsch (new Eta) scheme [16], Lin microphysics scheme [17], Yonsei University planetary boundary layer scheme [18], Rapid Radiative Transfer Model for long wave radiation physics scheme [19] and Dudhia scheme for shortwave radiation [20].

The initial background analysis data are from the National Centers for Environmental Prediction (NCEP) Final Analysis (FNL) data $\left(1^{\circ} \times 1^{\circ}\right.$ horizontal resolution). The lateral boundary conditions are updated every 6 hours. The con- 
ventional surface and sounding data are assimilated with the three-dimensional variation data assimilation system (WRF-3DVAR) modules (Barker et al., 2004). All experiments are integrated from 1200 UTC 9 September 2010 to 1800 UTC 10 September 2010.

Three experiments were performed to understand the response of typhoon Meranti (2010) to terrain height and land surface processes (Table 1). The control experiment (CTRL) simulated track, moving speed and intensity are basically matched well with the observations, and CTRL reproduces many features of typhoon Meranti (2010). The FLAT experiment was carried out to highlight the role of terrain height, where the terrain height was changed to zero and the terrain was completely eliminated, but other land surface physical processes were preserved. The SEA experiment was designed to compare land surface with ocean dynamics, where the land surface replaced by the sea (no terrain and land surface). A comparative study of the three experiments helped to evaluate its role of terrain height and land surface processes during the landfall of typhoon $\mathrm{Me}$ ranti (2010).

\section{Simulation Results}

\subsection{Track and Intensity}

Apparently, the simulated typhoon tracks from the SEA and FLAT experiments do not deviate much from that of CTRL, which are in very good agreement with that from JTWC. These suggest that the terrain has little effect on the typhoon track in this case study. This might be mainly due to the fact that Meranti (2010) was largely controlled by its large-scale environmental steering airflow.

In CTRL experiment, the simulated maximum surface wind speed (MSW) and minimum sea level pressure (MSLP) agree well with that from JTWC. However, the simulated intensity from CTRL is much weaker than that from FLAT experiment, where the removal terrain results in a more intense typhoon. In comparison, landing typhoon lacks moisture and heat sources that ocean provided, thus, its intensity from SEA experiment is much stronger than that from CTRL and FLAT experiment. We do note here that SEA experiment sustains an almost invariant structure when the typhoon passes through the hypothetical sea level.

\subsection{Rainfall Asymmetry}

The distribution of 12-hourly accumulated rainfall from 16:30UTC 9 September to $04: 30$ UTC 10 September 2010 , which are derived from 3-hourly $0.25^{\circ} \times 0.25^{\circ}$

Table 1 . The settings of the sensitivity experiments.

\begin{tabular}{cc}
\hline Experiment & Description \\
\hline CTRL & Control experiment with original terrain data \\
FLAT & Same as CTRL except that the terrain height of Land set to $0 \mathrm{~m}$ \\
SEA & Same as CTRL except that Land is replaced by Ocean \\
\hline
\end{tabular}


TRMM (the Tropical Rainfall Measuring Mission) 3B42 product, depicts that the heavy rainfall occurs on the left side of the storm track (Figure 3). Experiments show that terrain height has an important effect on landing typhoon rainfall. Model simulated accumulated rainfall shows that the model is able to reproduce the heavy rainfall with good agreement with TRMM observations. All simulations described the rainfall distributions well, but they differed in rainfall amount. The CTRL experiment produced a more realistic simulation of heavy rainfall than that from no-terrain run (FLAT) and SEA experiment. However, the SEA experiment underestimated the quantity of rainfall, which produced less rainfall than the other two experiments. Moist air over real terrain can lead to much heavier rainfall in CTRL experiment than that in FLAT and SEA experiment, because the formation and propagation of rainfall are closely related to terrain height and land surface processes, which have a great impact on the intensity of precipitation.

These precipitation differences are generally induced by both complex terrain and synoptic scale convection ascent. The difference between the CTRL and FLAT experiment (CTRL-FLAT) are due to the effects of terrain height forcing. The FLAT experiment, the run without mountains, receives less rainfall than that in the CTRL experiment. Figure 4(a) shows precipitation difference between the CTRL and FLAT experiment, which helped to better gauge the role of terrain height during the landfall of typhoon. In contrast, Figure 4(b) presents
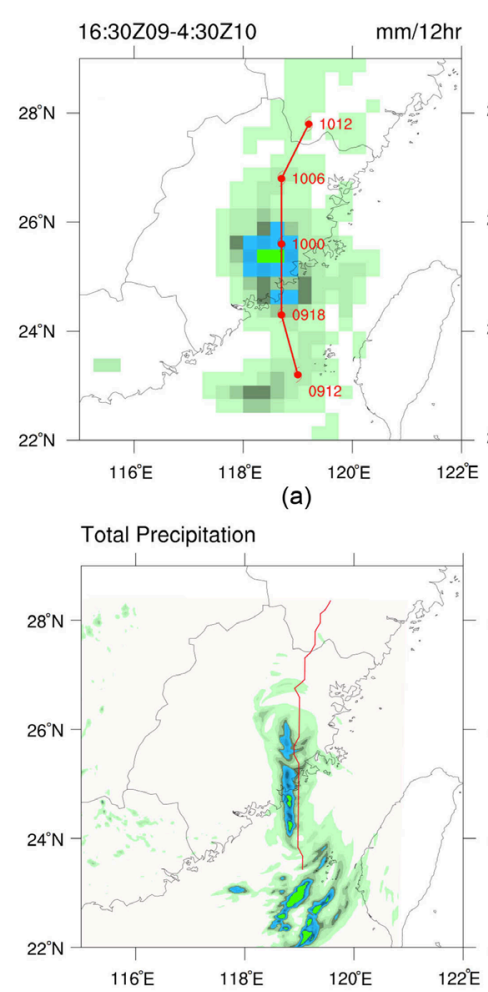

(c)

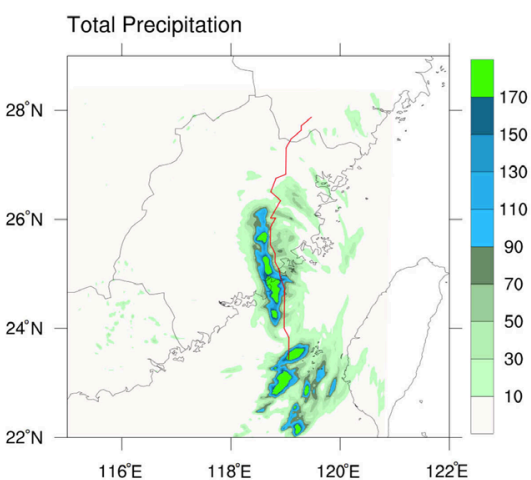

(b)

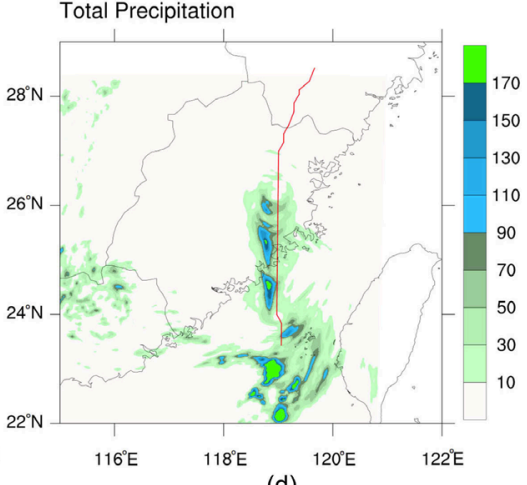

(d)

Figure 3. 12-h rainfall (units: $\mathrm{mm}$ ) from 16:30UTC 09 Sep. 2010 to 04:30UTC 10 Sep. 2010, overlaying the storm tracks (red line): (a) TRMM; (b) CRTL; (c) FLAT; and (d) SEA. 


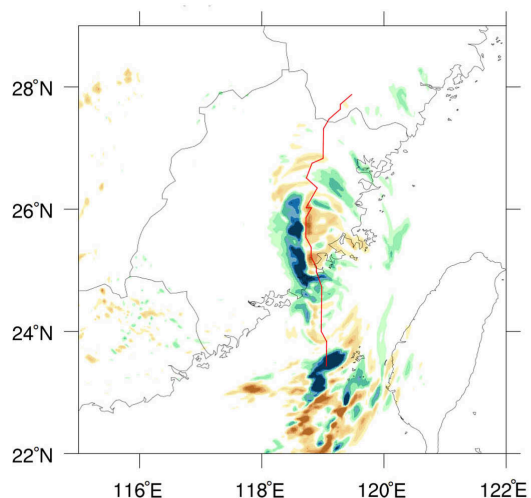

(a)

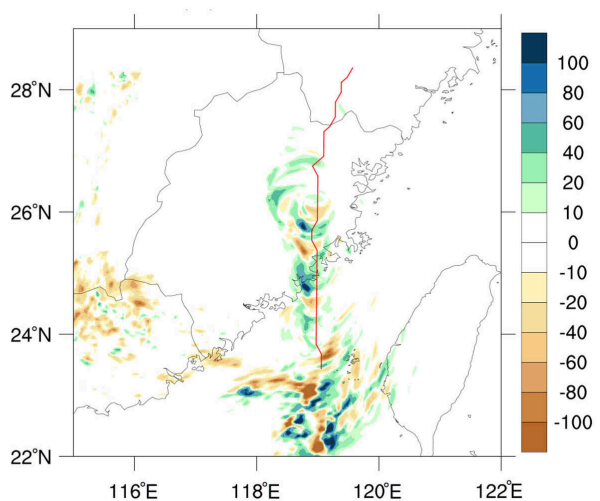

(b)

Figure 4. The 12-hourly accumulated rainfall (units: $\mathrm{mm}$ ) from 16:30UTC 09 Sep. 2010 to 04:30UTC 10 Sep. 2010, along the storm tracks (red line): (a) CRTL-FLAT; (b) FLAT-SEA.

the difference in rainfall amounts between the FLAT and SEA experiment (FLAT-SEA). The asymmetric rainfall distribution may arise from the land-sea contrast. However, we found that the terrain height had a greater contribution to the rainfall amounts during a landfall of typhoon. When the forcing is mainly terrain height, the rainfall distribution remains concentrated along the left side of the storm track. A comparison of these two panels of Figure 3 and Figure 4 suggest that mountainous terrain acts to enhance rainfall from a synoptic scale typhoon and its convective systems.

During the 3-hourly precipitation prior to landfall (from 18UTC to 21UTC 09 September 2010) to that after landfall (from 21UTC 09 to 00UTC 10 September 2010), significant rainfall differences between the CTRL and FLAT experiment indicate that typhoon Meranti (2010) has an evident rainfall enhancement after landfall, which was induced by terrain height (Figure 5). In comparison, the typhoon rainfall differences between FLAT and SEA run, experiences a negligible enhancement before and after landfall, which was induced by land processes (Land-Sea Contrast). On the other hand, Figure 5 presents some agreement with Figure 4, where precipitation generally remains concentrated along the left side of Meranti (2010). All the results of simulations suggest that precipitation intensities in this case are strongly linked to terrain height, which could be the major factor that enhances rainfall and experiences some noticeable changes.

\subsection{Typhoon Structure Asymmetry}

The influences of terrain height on the radial-vertical wind of Meranti (2010) are pronounced in CTRL experiment. Figure 6 and Figure 7 compare the simulated radial-vertical wind, equivalent potential temperature, and the mean relative angular momentum (RAM) before and after Meranti (2010) landing, respectively. All the simulation results indicate that typhoon Meranti (2010) are highly asymmetric, and on the right side of its center there is a greater RAM than on the left side of its center before and after landfall. Another obvious feature in Figure 6 and Figure 7 shows that the maximum deep convection is located at 


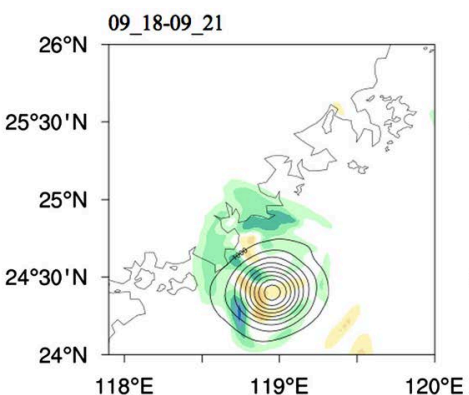

(a)

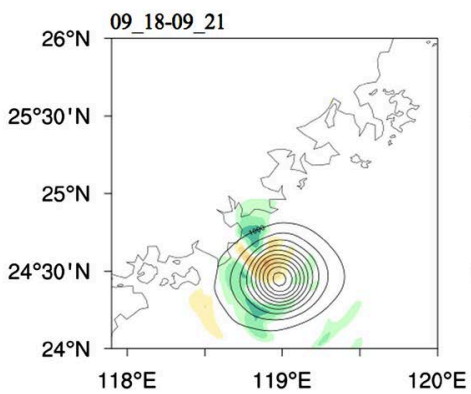

(c)

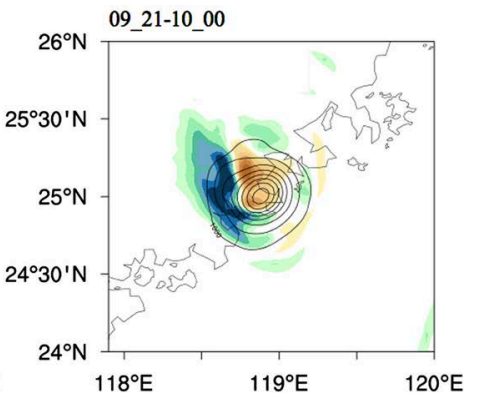

(b)

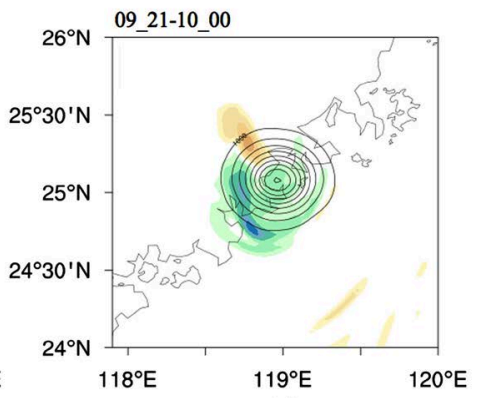

(d)

Figure 5. The 3-hourly accumulated precipitation (units: $\mathrm{mm}$ ) from 18UTC to 21UTC 09 Sep. 2010 before landfall (a) CTRL-FLAT and (c) FLAT-SEA, and from 21UTC 09 to 00UTC 10 Sep. 2010 after landfall (b) CTRL-FLAT and (d) FLAT-SEA, respectively.
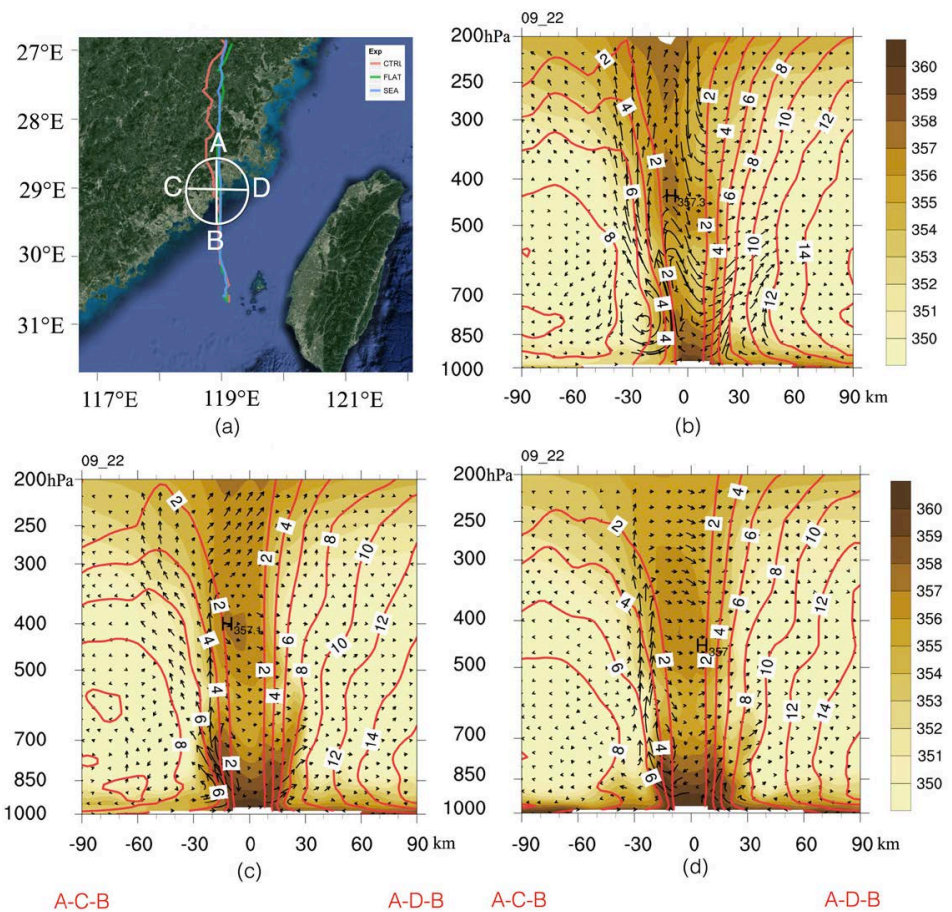

Figure 6. Along-track arch A-C-B and cross-track arch A-D-B vertical cross sections of the mean equivalent potential temperature (shading, units: $\mathrm{K}$ ), angular momentum (contour, units: $10^{5} \mathrm{~m}^{2} \cdot \mathrm{s}^{-1}$ ), and radial-vertical wind vectors within $90 \mathrm{~km}$ radius of typhoon center prior to landfall (20UTC 09 Sept. 2010). (a) Terrain and Storm track; (b) CTRL; (c) FLAT; and (d) SEA. 


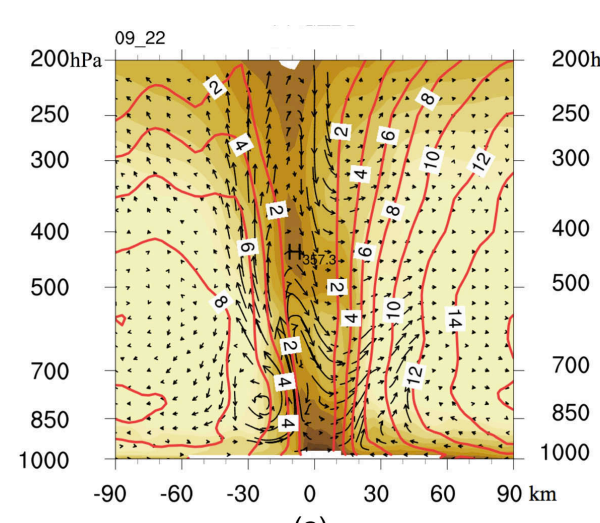

(a)
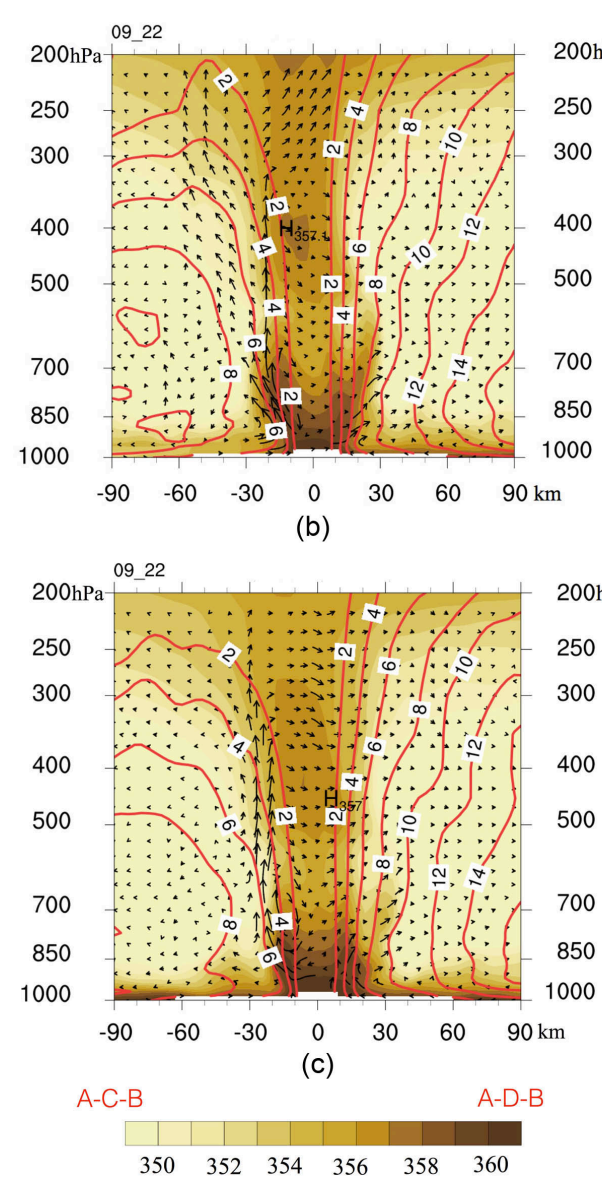

(b)

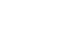

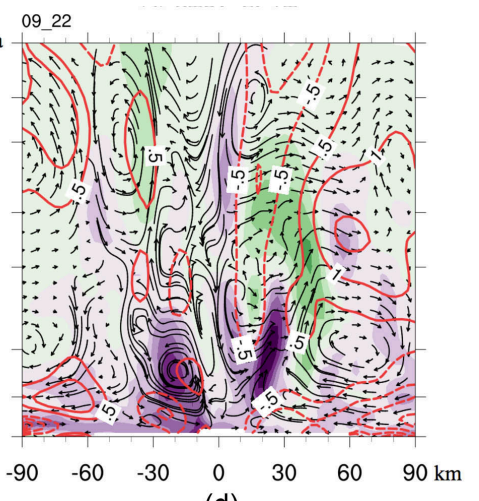

(d)
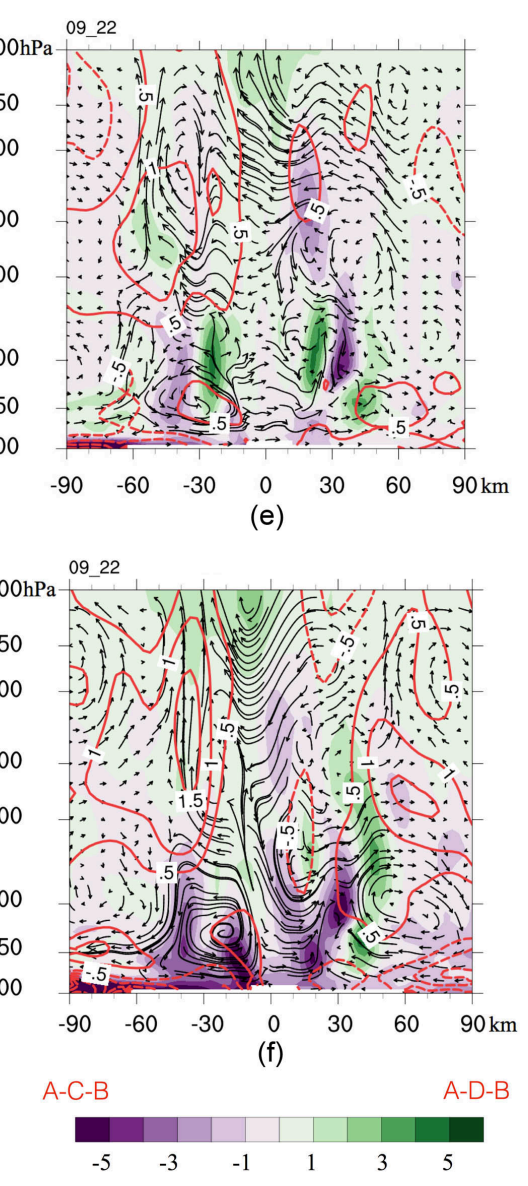

Figure 7. As in Figure 6, but for typhoon after landfall (22UTC09 Sept. 2010): (a) CTRL; (b) FLAT; (c) SEA; (d) CTRL-FLAT; (e) FLAT-SEA; and (f) CTRL-SEA.

the left side of the storm center in all the simulation results. Particularly, as depicted by the vertical-radial wind vectors in Figure 7(a), in CTRL experiment, a well-developed secondary circulation with cyclonic convergence is located within the left side of the typhoon center when Meranti (2010) passes over land. This secondary circulation helps to highlight the importance of terrain height in the enhanced post-landfall precipitation.

When the differences between the radial-vertical wind vectors in the CTRL and FLAT experiments are concerned, the radial-vertical wind disturbances 
caused by terrain height exhibit a high degree of left and right asymmetry along the direction of Meranti (2010) movement. Figure 7(d) shows that there is a significant cyclonic circulation anomaly within the eye-wall region. The perturbation cyclonic flow is stronger to the left than to the right within the eye wall regions, and the strongest anomaly anticyclone winds within the outer core region are found on the right side of the storm motion. Both the perturbation cyclonic flow and anticyclone are stronger in the lower troposphere with extending the upper troposphere and lower stratosphere. The most striking feature is that the strongest cyclonic flow has much higher negative perturbation potential temperature within the eye wall region than the surrounding outer core atmosphere. Secondly, when the radial-vertical wind differences between the FLAT and SEA are concerned, the land-sea contrast could also produce remarkably asymmetric structures in Meranti (2010) making landfall. Figure 7(e) shows that the perturbation anticyclonic flow in the upper troposphere and lower stratosphere overlies the lower tropospheric cyclonic flow within the inner core atmosphere. Small but persistent features are the fluctuating structures of perturbation potential temperatures in Meranti (2010) circulations. Finally, when the radial-vertical wind differences between CTRL and SEA are concerned, Figure $7(\mathrm{f})$ indicates that at the lower troposphere, cyclonic flow and anticyclone in CTRL-SEA are much stronger than that in CTRL-FLAT. However, it is worth pointing out that above the upper troposphere, perturbation vortex flow in CTRL-SEA is much weaker than that in CTRL-FLAT, the effects of terrain height and land surface tend to cancel each other out along the west of storm track.

The asymmetric structure during the landfall of a typhoon was usually accompanied by the highly asymmetric rainfall distribution. The convective asymmetry in Meranti (2010) with the deep convection located on the west side of the eye-wall, as well as the terrain height enhanced convection, could explain why the accumulated rainfall amount and pattern in terrain experiment (CTRL-FLAT) differs substantially from no-terrain simulations (FLAT-SEA, Land-Sea Contrast experiment) during the landfall of Meranti (2010).

\section{Comparison with Theoretical Model}

In this section, we study the mechanism that leads to secondary circulation and enhanced rainfall, which can be understood from the evolving azimuthal component horizontal vorticity that represents tropical cyclones in cylindrical axisymmetric coordinate systems. The momentum equations for an axisymmetric vortex in cylindrical polar coordinates are of the form:

$$
\begin{gathered}
\frac{\partial u}{\partial t}+u \frac{\partial u}{\partial r}+w \frac{\partial u}{\partial z}-\frac{v^{2}}{r}-f v=-\frac{1}{\rho} \frac{\partial p}{\partial r}+D_{u} \\
\frac{\partial w}{\partial t}+u \frac{\partial w}{\partial r}+w \frac{\partial w}{\partial z}=-\frac{1}{\rho} \frac{\partial p}{\partial z}-g+D_{w}
\end{gathered}
$$

where $(u, v, w)$ are the three dimensional velocity vectors, $p$ and $\rho$ are the 
pressure and density, respectively, and $D_{u}$ and $D_{w}$ represent the sub-grid-scale vertical mixing and horizontal smoothing, respectively.

It is assumed that the basic state of the airflow satisfies the gradient wind balance and static equilibrium. The linearized momentum equations for (5.1) and (5.2) are given:

$$
\begin{gathered}
\frac{\partial u}{\partial t}+u_{0} \frac{\partial u}{\partial r}=-\frac{1}{\rho} \frac{\partial p}{\partial r}+D_{u} \\
\frac{\partial w}{\partial t}+u_{0} \frac{\partial w}{\partial r}=-\frac{1}{\rho} \frac{\partial p}{\partial z}+g \frac{\theta^{\prime}}{\theta}+D_{w}
\end{gathered}
$$

where $u_{0}$ is the basic state radial velocity, and the buoyancy field B given by

$$
B=-g \frac{\theta^{\prime}}{\bar{\theta}}
$$

where $\theta=\bar{\theta}+\theta^{\prime}$, and $\theta^{\prime}$ is the perturbation potential temperature, $\bar{\theta}=\bar{\theta}(z)$ is a fixed reference potential temperature. With Coriolis and compressibility neglected, the total tendency of azimuthal-component horizontal vorticity is given by

$$
\frac{\mathrm{d} \eta}{\mathrm{d} t}=\frac{\partial B}{\partial r}+D
$$

where $\eta=\frac{\partial u}{\partial z}-\frac{\partial w}{\partial r}$, and the first term on the ride-hand side represents baroclinic generation of azimuthal-component horizontal vorticity through buoyancy gradients, and D represents sub-grid-scale turbulent stresses.

Following Smolarkiewicz and Rotunno [21], we consider the steady azimuthal-component horizontal vorticity equation linearized about a constant wind in the radial direction $u_{0}$ :

$$
u_{0} \frac{\partial \eta}{\partial r}=\frac{\partial B}{\partial r}
$$

Equation (5.7) reminds us that azimuthal-component horizontal vorticity $\eta$ is generated through baroclinicity. Using $\eta=0$ at $r=\infty$, one can show further that

$$
\eta=\frac{B}{u_{0}}=-\frac{g}{u_{0}} \frac{\theta^{\prime}}{\bar{\theta}}
$$

These results support the idea that secondary circulation with positive vorticity along the left side of the storm track $\left(u_{0}>0\right)$ is associated with negative perturbation potential temperature (Figure $7(d)$ ). The higher negative perturbation potential temperatures coincide with the observed rainfall maximum and secondary circulation and may be related directly to the enhanced deep convective activity excited by terrain height.

The steady thermal equation that represents tropical cyclones in the cylindrical axisymmetric coordinates can be written as

$$
u_{0} \frac{\partial B}{\partial r}=N^{2} w
$$


where $N^{2} \equiv g \frac{\partial \ln \bar{\theta}}{\partial z}$.

Let the terrain contour be specified as

$$
z_{S}(r)=\frac{h_{m} a^{2}}{a^{2}+r^{2}}
$$

If the flow is hydrostatic, the expression for the displacement of a streamline from its height far upstream is

$$
\delta(r, z)=\left(\frac{\bar{\rho}}{\rho_{0}}\right)^{-1 / 2} h_{m} a \frac{a \cos \left(\frac{N}{u_{0}} z\right)-r \sin \left(\frac{N}{u_{0}} z\right)}{a^{2}+r^{2}}
$$

where $\bar{\rho}=\bar{\rho}(z)$ and $\delta(r, z)$ are density and perturbation displacement field.

Along with (5.3)-(5.4), the vertical velocity may be obtained from the relation

$$
w=u_{0} \frac{\partial \delta(r, z)}{\partial r}
$$

Finally, (5.9) and (5.12) lead to

$$
B=N^{2} \delta(r, z)
$$

Using (5.8) and (5.13), we can show that

$$
\eta=\frac{N^{2}}{u_{0}} \delta(r, z)
$$

When $N^{2}<0$ and the perturbation displacement $\delta(r, z)<0$, then the positive azimuthal vorticity is generated through orography and convection.

Following Smith (1979) [22], then the local precipitation rate over terrain is given by

$$
P=\varepsilon \rho_{a} q_{0} \overrightarrow{V_{0}} \cdot \nabla z_{S}
$$

where $\rho_{a}$ and $q_{0}$ are the air density and water vapor mixing ratio at the ground, respectively, $\nabla z_{S}$ is local terrain slope, and $\varepsilon$ is constant precipitation efficiency.

Considering the enhanced convection, the incoming airflow is $u_{0}$ and $\delta$ is terrain-forced perturbation displacement, we obtain

$$
P=\varepsilon \rho_{a} q_{0} u_{0}\left(\frac{\bar{\rho}}{\rho_{0}}\right)^{-1 / 2} h_{m} a \frac{\left(\left(r-r_{0}\right)^{2}-a^{2}\right) \sin \left(\frac{N}{u_{0}} z\right)-2\left(r-r_{0}\right) a \cos \left(\frac{N}{u_{0}} z\right)}{\left(a^{2}+\left(r-r_{0}\right)^{2}\right)^{2}}
$$

Equation (5.16) suggests that the precipitation rate is proportional to the wind speed $u_{0}$, moisture content $q_{0}$ and the mountain height $h_{m}$.

\section{Conclusion and Discussion}

Observations and three numerical sensitivity experiments show that Meranti rainstorm is mainly located on the left side of the storm movement, possibly due to the fact that the deep convection is mainly located on the left side of the ty- 
phoon movement. However, the underlying surface of the typhoon had changed remarkably after the typhoon Meranti landed, and the elevated terrain can favor strong deep convection, resulting in a secondary circulation in perturbed radial-vertical wind vectors of typhoon, which can enhance typhoon precipitation. It is worth pointing out that the enhanced rainfall may be fundamentally caused by the terrain height.

We have innovatively developed a new highly simplified theoretical model to explain the possible physical mechanism of secondary circulation and enhanced rainfall caused by terrain height, when a typhoon passes over land. As pointed out by the theoretical analysis, where there is a positive perturbation potential temperature, the buoyancy is negative, there is a negative horizontal azimuthal vorticity distribution, and where there is a negative perturbation potential temperature, the buoyancy is positive and there is a positive horizontal azimuthal vorticity distribution with cyclone circulation (Figure 7). According to the relationship between buoyancy and perturbation displacement, when the convection is unstable, there is a horizontal positive vorticity where the perturbation displacement is negative. The above analysis is said that lee vortices are generated through baroclinicity, when a typhoon passes over complex terrain. Finally, we also like to mention that the enhanced convection induced by terrain height provided a favorable condition for the local heavy rainfall during the landfall of a typhoon. It is hypothesized that the extra amount of rainfall is due to buoyancy processes generated by terrain height, we will in detail address this issue in the future.

\section{Acknowledgements}

This work supported by National key basic research and development plan (2015CB953900) and the National Natural Science Foundation of China (Grant no. 41176005).

\section{Conflicts of Interest}

The authors declare no conflicts of interest regarding the publication of this paper.

\section{References}

[1] Needham, H.F., Keim, B.D. and Sathiaraj, D. (2015) A Review of Tropical Cyclone Generated Storm Surges: Global Data Sources, Observations, and Impacts. Reviews of Geophysics, 53, 545-591. https://doi.org/10.1002/2014RG000477

[2] Chavas, D.R., Lin, N. and Emanuel, K. (2015) A Model for the Complete Radial Structure of the Tropical Cyclone Wind Field. Part 1: Comparison with Observed Structure. Journal of the Atmospheric Sciences, 72, 3647-3662. https://doi.org/10.1175/JAS-D-15-0014.1

[3] Reed, A.J., Mann, M.E., Emanuel, K.A., Lin, N., Horton, B.P., Kemp, A.C. and Donnelly, J.P. (2015) Increased Threat of Tropical Cyclones and Coastal Flooding to New York City during the Anthropogenic Era. Proceedings of the National Academy of Sciences of the United States of America, 112, 12610-12615. 
https://doi.org/10.1073/pnas.1513127112

[4] Nguyen, L., Molinari, J. and Thomas, D. (2014) Evaluation of Tropical Cyclone Center Identification Methods in Numerical Models. Monthly Weather Review, 142, 4326-4339. https://doi.org/10.1175/MWR-D-14-00044.1

[5] Stevenson, S.N., Corbosiero, K.L. and Molinari, J. (2014) The Convective Evolution and Rapid Intensification of Hurricane Earl (2010). Monthly Weather Review, 142, 4364-4380. https://doi.org/10.1175/MWR-D-14-00078.1

[6] Jones, S.C. (2004) On the Ability of Dry Tropical-Cyclone-Like Vortices to Withstand Vertical Shear. Journal of the Atmospheric Sciences, 61, 114-119. https://doi.org/10.1175/1520-0469(2004)061<0114:OTAODT>2.0.CO;2

[7] Frank, W.M. and Ritchie, E.A. (2001) Effects of Environmental Flow Upon Tropical Cyclone Structure of Numerically Simulated Hurricanes. Monthly Weather Review, 129, 2049-2069. https://doi.org/10.1175/1520-0493(2001)129<2249:EOVWSO >2.0.CO;2

[8] Yang, L., Fei, J.F., Huang, X.G., Cheng, X.D., Yang, X.R., Ding, J.L. and Shi, W.L. (2016) Asymmetric Distribution of Convection in Tropical Cyclones over the Western North Pacific Ocean. Advances in Atmospheric Sciences, 33, 1306-1321. https://doi.org/10.1007/s00376-016-5277-x

[9] Nguyen, L. and Molinari, J. (2015) Simulation of the Down-Shear Reformation of a Tropical Cyclone. Journal of the Atmospheric Sciences, 72, 4529-4551. https://doi.org/10.1175/JAS-D-15-0036.1

[10] Molinari, J. and Vollaro, D. (2014) Symmetric Instability in the Outflow Layer of a Major Hurricane. Journal of the Atmospheric Sciences, 71, 3739-3746. https://doi.org/10.1175/JAS-D-14-0117.1

[11] Wei, N. and Li, Y. (2013) A Modeling Study of Land Surface Process Impacts on Inland Behavior of Typhoon Rananim (2004). Advances in Atmospheric Sciences, 30, 367-381. https://doi.org/10.1007/s00376-012-1242-5

[12] Yang, M.J., Zhang, D.L., Tang, X.D. and Zhang, Y. (2011) A Modeling Study of Typhoon NARI (2001) at Landfall: 2. Structural Changes and Terrain Induced Asymmetries. Journal of Geophysical Research, 116, 1-18.

https://doi.org/10.1029/2010JD015445

[13] Ramsay, H.A. and Leslie, L.M. (2008) The Effects of Complex Terrain on Severe Landfalling Tropical Cyclone Larry (2006) over Northeast Australia. Monthly Weather Review, 136, 4334-4354. https://doi.org/10.1175/2008MWR2429.1

[14] Bender, M.A., Tuleya, R.E. and Kurihara, Y. (1987) A Numerical Study of the Effect of Island Terrain on Tropical Cyclones. Monthly Weather Review, 115, 130-155. https://doi.org/10.1175/1520-0493(1987)115<0130:ANSOTE >2.0.CO;2

[15] Skamarock, W., et al. (2008) A Description of the Advanced Research WRF Version 3. Technical Report, NCAR.

[16] Kain, J.S. (2004) The Kain-Fritsch Convective Parameterization: An Update. Journal of Applied Meteorology, 43,170-181. https://doi.org/10.1175/1520-0450(2004)043<0170:TKCPAU>2.0.CO;2

[17] Lin, Y.L., Farley, R.D. and Orville, H.D. (1983) Bulk Parameterization of the Snow Field in a Cloud Model. Journal of Climate and Applied Meteorology, 22, 1065-1092. https://doi.org/10.1175/1520-0450(1983)022<1065:BPOTSF>2.0.CO;2

[18] Hong, S.Y., Noh, Y. and Dudhia, J. (2006) A New Vertical Diffusion Package with an Explicit Treatment of Entrainment Processes. Monthly Weather Review, 134, 2318-2341. https://doi.org/10.1175/MWR3199.1 
[19] Dudhia, J. (1989) Numerical Study of Convection Observed during the Winter Monsoon Experiment Using a Mesoscale Two-Dimensional Model. Journal of the Atmospheric Sciences, 46, 3077-3107. https://doi.org/10.1175/1520-0469(1989)046<3077:NSOCOD>2.0.CO;2

[20] Barker, D.M., Huang, W., Guo, Y.R., Bourgeois, A.J. and Xiao, Q.N. (2004) A Three-Dimensional Variational Data Assimilation System for MM5: Implementation and Initial Results. Monthly Weather Review, 132, 897-914. https://doi.org/10.1175/1520-0493(2004)132<0897:ATVDAS>2.0.CO;2

[21] Smolarkiewicz, P.K. and Rotunno, R. (1989) Low Froude Number Flow Past Three-Dimensional Obstacles. Part one: Baroclinically Generated Lee Vortices. Journal of the Atmospheric Sciences, 46, 1154-1164. https://doi.org/10.1175/1520-0469(1989)046<1154:LFNFPT >2.0.CO;2

[22] Smith, R.B. (1979) The Influence of Mountains on the Atmosphere. Advances in Geophysics, 21, 87-230. https://doi.org/10.1016/S0065-2687(08)60262-9 